\title{
Phenotypic and genotypic characteristics of community- acquired and hospital-acquired carbapenem-resistant Enterobacteriaceae in patients with liver cirrhosis at the National Liver Institute of Egypt
}

\author{
Samah M. Awad, MD; ${ }^{1}$ Samar E. Ghanem, MD; ${ }^{2}$ Marwa L. Helal, MD; ${ }^{2}$ Gamalat A. Elgedawy, MD; ${ }^{2}$ Fatma O. Khalil, MD; ${ }^{1}$ \\ Marwa Fikry, MD; ${ }^{3}$ Maha M. El Sabawy, MD; ${ }^{4}$ Mervet A. Moustafa, MD; ${ }^{4}$ Mohammed A. Sarhan, MB.BCh, PhD ${ }^{1,5}$ \\ ${ }^{1}$ Department of Clinical Microbiology and Immunology and Molecular Microbiology in Liver and GIT, National Liver Institute, Menoufia University, Egypt \\ ${ }^{2}$ Department of Clinical Biochemistry and Diagnostic Molecular Biology, National Liver Institute, Menoufia University, Egypt \\ ${ }^{3}$ Department of Epidemiology and Preventive Medicine, National Liver Institute, Menoufia University, Egypt \\ ${ }^{4}$ Department of Hepatology and Gastroenterology, National Liver Institute, Menoufia University, Egypt \\ 5Infection Prevention and Control, Alberta Health Services, Alberta, Canada
}

Corresponding author:

Mohammed A. Sarhan, MB.BCh, PhD

Tel: 780-267-7321

sarhan128@yahoo.com

\begin{abstract}
Background: Carbapenem-resistant Enterobacteriaceae (CRE) is considered one of the most urgent public health problems worldwide with associated high morbidity and mortality rates. CRE has both community-acquired (CA) and hospital-acquired (HA) danger because of the transmissible nature of plasmids.

Objectives: We aimed to compare the phenotypic and genotypic characteristics of carbapenemase genes in CRE isolates causing CA and HA infections in cirrhotic patients and the distribution of carbapenemase genes in both settings.

Method: CRE isolates were taken from 38 recruited cirrhotic patients at the National Liver Institute at Menoufia University in Egypt between January 2017 and January 2018 with Enterobacteriaceae isolates resistant to at least one carbapenem. Isolates were identified and described by conventional techniques and confirmed by the VITEK 2 system, which was also used for antimicrobial susceptibility and the detection of extended-spectrum $\beta$-lactamase production. We then phenotypically and genotypically characterized all isolates for the presence of the most prevalent carbapenemase enzymes (Klebsiella pneumoniae carbapenemase [KPC], Verona integron metallo-betalactamases [VIM], New Delhi metallo-beta lactamase [NDM], and oxacillinase-48 [OXA-48]) and genes using multiplex polymerase chain reaction confirmed results.

Results: All CRE isolates included in this study were resistant to all carbapenems tested and susceptible to colistin, while 20 of the 38 isolates were sensitive to tigecycline. Among the $24 \mathrm{HA}$ CRE isolates, nine isolates (37.5\%) contained OXA-48, three (12.5\%) contained both OXA-48 and NDM-1, two contained KPC (8.3\%), one carried NDM-1 (4.2\%), and one included VIM (4.2\%). The OXA-48 gene was the most frequent gene in both groups, and no statistically significant difference was found between the two groups in regards to prevalence.

Conclusion: OXA-48 CRE is the most prevalent carbapenemase gene in Egyptian cirrhotic patients with similar phenotypic and genotypic characteristics to CA cases. This indicates the equal prevalence of CRE in community and hospital settings.
\end{abstract}

\section{KEYWORDS}

Carbapenem-resistant Enterobacteriaceae; cirrhotic patients

\section{INTRODUCTION}

Rapidly emerging antimicrobial-resistant Enterobacteriaceae have been noted frequently with decompensated liver cirrhosis patients due to recurrent hospitalizations and repeated exposure to antibiotics either for treatment or prophylactic purposes. In addition, although carbapenem-resistant Enterobacteriaceae (CRE) are considered hospital-acquired (HA) pathogens, community-acquired (CA) CRE are also a threat and the knowledge about community-acquired CRE is limited [1, 2].

CRE are capable of inactivating carbapenem via different mechanisms, such as the overproduction of ampC enzymes, extended-spectrum beta-lactamase (ESBLs), carbapenemase enzymes that inactivate the $\beta$-lactam antibiotics, including carbapenems, efflux pumps, and deletion of porins [3]. Although CRE are initially considered HA pathogens, CA CRE are also noted [4].The most clinically important carbapenmases are Klebsiella pneumoniae carbapenemase (KPC) in the Ambler class A category, Verona integron metallo-beta-lactamases types (VIM), imipenemase, New Delhi metallo-betalactamase-1 (NDM-1) in the class B category, and oxacillinase-48 (OXA-48) in the class D category [5]. The dissemination of KPC, VIM,

Acknowledgements: All authors contributed to conception, design, data analysis, and writing the manuscript.

Conflicts of interest: None.

Funding: Local and self-funding sources. 
NDM, and OXA-48 among K. pneumoniae and Escherichia coli has been emerging in different countries [6].

NDM and OXA-48 producers are both $\mathrm{HA}$ and $\mathrm{CA}$ pathogens, whereas KPC producers are mainly HA isolates [7]. The activity of carbapenemase enzymes is identified by phenotypic assays, while carbapenemase encoding genes are identified by molecular assays [8, 9].

In the current study, we investigated the phenotypic and genotypic characteristics of CA and HA CRE isolates from cirrhotic patients admitted to the National Liver Institute (NLI) at Menoufia University in Egypt.

\section{METHODS}

\section{Design}

The study was performed from January 2017 to January 2018 at the NLI (Menoufia University, Egypt). NLI is a university hospital with a capacity of 320 beds that provides medical services for 107,450 hepatic patients annually.

The study was approved by the NLI Research Ethics Committee and the Research Ethics Committee of Menoufia University's Faculty of Medicine. Informed consent was obtained from all participants before their enrollment in the study.

\section{Patients}

A total of 38 Enterobacteriaceae isolates resistant to at least one carbapenem were isolated from different clinical specimens (e.g., blood, urine, sputum, wound, stool, and swabs from central lines and urinary catheters). Patient consent was ensured.

\section{Diagnostic criteria}

Inclusion criteria

HA CRE were isolated from patients who were hospitalized for $>48$ hours. CRE is considered CA if the infection was present on admission or developed less than 48 hours after hospitalization. The definition of infection or colonization was followed by the guidelines published by the Centers for Disease Control and Prevention.

\section{Exclusion criteria}

Enterobacteriaceae isolates that were sensitive to carbapenems or associated with asymptomatic colonization were excluded. Duplicate isolates from the same patient were also excluded, unless they were isolated from different specimens with a distinguishable susceptibility pattern.

\section{Bacterial cultures and antimicrobial susceptibility}

Isolates were plated on blood agar and MacConkey agar (Oxoid, UK), depending on the type of clinical specimens. Cultures were then examined macroscopically for colonial morphology and a Gram stain was performed on suspected colonies. All Enterobacteriaceae isolates were selected then subcultured at $37^{\circ} \mathrm{C}$ overnight on MacConkey agar media for purity and further identification tests. Further, confirmation of the isolates was performed using the automated VITEK 2 Compact system (BioMérieux, France) and Gram-negative (GN) cards following the manufacturer's instructions.
Antimicrobial susceptibility and production of ESBL were determined using the VITEK 2 Compact system and AST-GN73 cards following the manufacturer's instructions. Confirmed isolates were stored in nutrient broth supplemented with $16 \%$ glycerol at $-80^{\circ} \mathrm{C}$ until used for phenotypic and genotypic characterization [10]. All CRE isolates were then tested for the presence of the most prevalent carbapenemase enzymes (KPC, VIM, NDM, and OXA-48) and genes by phenotypic (Modified Hodge Test) [11] and genotypic methods (multiplex polymerase chain reaction [PCR]) [12].

\section{Statistical method}

Data was collected and entered to the computer using the SPSS program for statistical analysis (v. 18, Chicago, IL). Data were entered as numerical or categorical. Numerical data were shown as mean and standard deviation (SD). Student's t-test was done to compare means and SD of two sets of numerical data. Categorical data were expressed as frequency and percent (\%) and a chi-squared test $\left(\mathrm{x}^{2}\right)$ was used to study association. Whenever any of the expected cells were less than five, Fischer's exact test was used. $P$-value was considered statistically significant when it was less than 0.05 .

\section{RESULTS}

All CRE isolates included in this study were resistant to all carbapenems tested and susceptible to colistin, while 20 out of 38 isolates were sensitive to tigecycline

Of the 38 CRE isolates, 24 patients had HA infection (63.2\%) and 14 patients $(36.8 \%)$ had CA infection. The mean age of

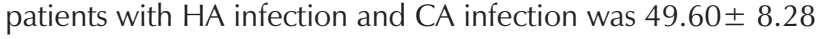
years and $45.56 \pm 10.25$ years, respectively. There was no significant difference between the two median ages $(P=0.06)$.

Infection, bacterial species, and carbapenemase gene distribution for HA and CA isolates are shown in Table 1. There was no statistically significant difference between the two groups.

The OXA-48 gene was the most frequent gene in CA and HA CRE. Among the $24 \mathrm{HA} \mathrm{CRE}$ isolates, nine isolates (37.5\%) contained OXA-48, three (12.5\%) contained both OXA-48 and NDM-1, two contained KPC (8.3\%), one contained NDM-1 $(4.2 \%)$, and one contained VIM (4.2\%). The prevalence of carbapenemase genes in CA isolates was as follows: $28.7 \%$ contained OXA-48, 14.3\% contained NDM-1, and 7.1\% contained both OXA-48 and NDM-1. Our study revealed that the OXA-48 gene was the most frequent gene in both groups and no statistically significant difference was found.

\section{DISCUSSION}

Phenotypic and genotypic characteristics in CA and HA CRE isolates causing infections in patients with liver cirrhosis were compared, and the role of carbapenemase genes and their distributions in both CA and $\mathrm{HA}$ infections were investigated. Exposure to antibiotics (such as carbapenem and quinolones), healthcare-associated interactions, the presence of indwelling devices, the use of mechanical ventilators, and comorbidities are 


\begin{tabular}{|c|c|c|c|}
\hline & $\begin{array}{c}\text { Hospital- } \\
\text { acquired } \\
\text { infections } \\
(n=24)\end{array}$ & $\begin{array}{c}\text { Community- } \\
\text { acquired } \\
\text { infections } \\
(n=14) \\
\end{array}$ & $P$-value \\
\hline \multicolumn{4}{|l|}{ Site of infection } \\
\hline \multirow{4}{*}{$\begin{array}{l}\text { Pneumonia } \\
\text { Urinary tract infection } \\
\text { Bacteremia } \\
\text { Wound infection }\end{array}$} & $3(12.5 \%)$ & $4(28.6 \%)$ & 0.21 \\
\hline & $5(20.8 \%)$ & $3(21.4 \%)$ & 0.96 \\
\hline & $4(16.7 \%)$ & $3(21.4 \%)$ & 0.71 \\
\hline & $4(16.7 \%$ & $4(28.6 \%)$ & 0.38 \\
\hline \multicolumn{4}{|l|}{ Bacterial species } \\
\hline \multirow{3}{*}{$\begin{array}{l}\text { Klebsiella pneumoniae } \\
\text { Escherichia coli } \\
\text { Morganella morgannii }\end{array}$} & 19 (79.2\%) & 9 (64.3\%) & 0.31 \\
\hline & $3(12.5 \%)$ & $5(35.7 \%)$ & 0.09 \\
\hline & $2(8.3 \%)$ & $0(0.0 \%)$ & 0.95 \\
\hline \multicolumn{4}{|l|}{ Carbapenemase gene } \\
\hline \multirow{2}{*}{$\begin{array}{l}\text { Negative for all } \\
\text { OXA-48 }\end{array}$} & $8(33.3 \%)$ & $6(42.8 \%)$ & \\
\hline & $9(37.5 \%)$ & $4(28.7 \%)$ & 0.77 \\
\hline \multirow{5}{*}{$\begin{array}{l}\text { NDM-1 } \\
\text { KPC } \\
\text { VIM } \\
\text { OXA- } 48 \text { and NDM-1 } \\
\text { KPC and NDM-1 }\end{array}$} & $1(4.2 \%)$ & $2(14.3 \%)$ & \\
\hline & $2(8.4 \%)$ & $0(0.0 \%)$ & \\
\hline & $1(4.2 \%)$ & $0(0.0 \%)$ & \\
\hline & $3(12.5 \%)$ & $1(7.1 \%)$ & \\
\hline & $0(0.0 \%)$ & $1(7.1 \%)$ & \\
\hline
\end{tabular}

all risk factors responsible for the higher incidence of CRE in these patients. Moreover, the acquisition and transfer of drug-resistant genes through plasmids and transposons and its spread to the community via the fecal-oral route may be responsible for the appearance of CA infections by CRE among such patients [13].

Previous studies reported nearly similar findings: Tang et al. (2016) found that $29.5 \%$ of 78 CRE cases were CA, but the study included colonization [4]. Sheng et al. (2016) reported that $21.3 \%$ of CRE cases were CA [14]. In contrast to our study, Miller \& Johnson (2015) and Thaden et al. (2014) reported lower incidence of CA CRE in comparison to HA $(9.8 \%$ and $5.6 \%$, respectively) $[15,16]$.

HA CRE was most frequently associated with urinary tract infections (UTI) (20.8\%), while in CA, pneumonia was the most frequent infection $(28.6 \%)$. This was consistent with other studies showing that UTIs were the most common HA infection, accounting for almost $40 \%$ of all nosocomial infections [17], while for CA, pneumonia is the most frequent infectious disease worldwide [18]. Also, Salerno et al. (2016) reported that UTIs, spontaneous bacterial peritonitis, and bacteremia were the most frequent $\mathrm{HA}$ infections in cirrhotic patients, while pneumonia was the most frequent CA infection (33\%) [19]. On the other hand, Tang et al. (2016) reported that pneumonia was the most common HA CRE infection in cirrhotic patients, followed by UTIs [4].

In regard to the type of bacteria, $K$. pneumoniae was the most common organism $(73.7 \%)$, followed by E. coli (21.1\%). Similar results were reported in many studies testing the presence of CRE among hospital and community samples $[3,16$, $20]$. However, others found that $E$. coli was the most common organism overall, followed by K. pneumoniae or Enterobacter cloacae (21-23).

The spread of CRE isolates into the community from healthcare settings or vice versa via the fecal-oral route and the highly transmissible nature of plasmid-borne carbapenemases may have contributed to the wide spread of CRE with comparable phenotypic characteristics in both settings.

Although no significant difference was found between the two CRE groups in regard to the genotypic characteristics and the prevalence of carbapenemase genes, OXA-48 was the most predominant gene among the $24 \mathrm{HA}$ CRE isolates $(37.5 \%)$ and the CA CRE isolates (28.7\%). Our observation was consistent with other studies that identified the OXA-48 gene as the most predominant gene [24].

The KPC and VIM genes were only detected in HA CRE, which could be due to the limited number of CA CRE cases.

OXA-48 was also reported to be commonly distributed in the Mediterranean region of Africa and Europe [25] and Saudi Arabia [26], which supports our findings. In addition to OXA48-like and NDM-1 genes, VIM was detected in one CRE isolate. The low detection rate of this gene may be attributed to the higher prevalence of this gene in Europe than Africa [25]. Moreover, the only Morganella morganii isolate detected in our study expressed the OXA-48 gene.

Interestingly, five out of the 38 CRE were found to co-express two carbapenemase genes. NDM-1 genes co-existed with OXA-48 genes in four isolates (three $\mathrm{HA}$ and one CA isolate) and co-existed with the KPC gene in one isolate, which confirms the high coexistence rate of different carbapenemases among Enterobacteriaceae isolates.

In conclusion, CRE have a wide distribution in the community with comparable phenotypic and genotypic characteristics to those in hospital settings, highlighting the overuse of antibiotics, adequate antibiotic empirical control, and the need for implementation of strict infection control guidelines in healthcare facilities. Further research involving more patients is needed in order to confirm our findings and highlight the need for antimicrobial stewardship. Coordination between infection control teams and healthcare workers is also crucial to prevent the spread of CRE.

\section{REFERENCES}

1. Perovic, O., Britz, E., Chetty, V., \& Singh-Moodley, A. (2016). Molecular detection of carbapenemase-producing genes in referral Enterobacteriaceae in South Africa: A short report. South African Medical Journal, 106(10), 975-977. doi: 10.7196/SAMJ.2016. v106i10.11300

2. Fernández, J., Bert, F., \& Nicolas-Chanoine, M. H. (2016). The challenges of multi-drug-resistance in hepatology. Journal of Hepatology, 65(5), 1043-1054. doi: 10.1016/j.jhep.2016.08.006

3. Nordmann, P., Poirel, L., \& Dortet, L. (2012). Rapid detection of carbapenemase-producing Enterobacteriaceae. Emerging Infectious Diseases, 18(9), 1503-1507. doi: 10.3201/eid1809.120355

4. Tang, H.-J., Hsieh, C.-F., Chang, P.-C., Chen, J.-J., Lin, Y.-H., Lai, C.-C., Chao, C.-M., \& Chuang, Y.-C. (2016). Clinical significance of community- and healthcare-acquired carbapenem-resistant Enterobacteriaceae isolates. PLOS ONE, 11(3), e0151897. doi: 10.1371/journal.pone.0151897 
5. Jacob, J. T., Klein, E., Laxminarayan, R., Beldavs, Z., Lynfield, R., Kallen, A. J., Ricks, P., Edwards, J., Srinivasan, A., Fridkin, S., Rasheed, K. J., Lonsway, D., Bulens, S., Herrera, R., McDonald, C. L., Patel, J., Limbago, B., Bell, M., \& Cardo, D. (2013). Vital signs: Carbapenem-resistant Enterobacteriaceae. Morbidity and Mortality Weekly Report, 62(9), 165-170. Retrieved from https:// jhu.pure.elsevier.com/en/publications/vital-signs-carbapenemresistant-enterobacteriaceae-4

6. Lee, C. R., Lee, J. H., Park, K. S., Kim, Y. B., Jeong, B. C., \& Lee, S. H. (2016). Global dissemination of carbapenemase-producing Klebsiella pneumoniae: Epidemiology, genetic context, treatment options, and detection methods. Frontiers in Microbiology, 7, 895. doi: 10.3389/fmicb.2016.00895

7. Nordmann, P., \& Poirel, L. (2014). The difficult-to-control spread of carbapenemase producers among Enterobacteriaceae worldwide. Clinical Microbiology and Infection, 20(9), 821-830. doi: 10.1111/1469-0691.12719

8. Moemen, D., \& Masallat, D. T. (2017). Prevalence and characterization of carbapenem-resistant Klebsiella pneumonia isolated from intensive care units of Mansoura University hospitals. Egyptian Journal of Basic and Applied Sciences, 4, 37-41. doi: 10.1016/j.ejbas.2017.01.001

9. El-Sweify, M. A., Gomaa, N. I., El-Maraghy, N. N., \& Mohamed, H. A. (2015). Phenotypic detection of carbapenem resistance among Klebsiella pneumoniae in Suez Canal University Hospitals, Ismailiya, Egypt. International Journal of Current Microbiology and Applied Sciences, 4(2),10-18. Retrieved from https:// www.ijcmas.com/vol-4-2/Mohammad\%20A.\%20El-Sweify, \%20 et\%20al.pdf

10. Murray, P. R., Baron, E. J., Jorgensen, J. H., Pfaller, M. A., \& Yolken, R. H. (2003). Manual of clinical microbiology (8th ed.). Washington, D.C.: American Society of Microbiology Press.

11. Anderson, K. F., Lonsway, D. R., Rasheed, J. K., Biddle, J., Jensen, B., McDougal, L. K., Carey, R. B., Thompson, A., Stocker, S., Limbago, B., \& Patel, J. B. (2007). Evaluation of methods to identify the Klebsiella pneumoniae carbapenemase in Enterobacteriaceae. Journal of Clinical Microbiology, 45(8), 2723-2725. doi: 10.1128/JCM.00015-07

12. Poirel, L., Walsh, T. R., Cuvillier, V., \& Nordmann, P. (2011). Multiplex PCR for detection of acquired carbapenemase genes. Diagnostic Microbiology and Infectious Disease, 70(1), 119-123. doi: 10.1016/j.diagmicrobio.2010.12.002

13. Kelly, A. M., Mathema, B., \& Larson, E. L. (2017). Carbapenemresistant Enterobacteriaceae in the community: A scoping review. International Journal of Antimicrobial Agents, 50(2), 127 134. doi: 10.1016/j.ijantimicag.2017.03.012

14. Sheng, W. H., Badal, R. E., \& Hseuh, P.-R. (2013). Distribution of extended-spectrum $\beta$-lactamases, AmpC $\beta$-lactamases, and carbapenemases among Enterobacteriaceae isolates causing intra-abdominal infections in Asia-Pacific region: Results of the Study for Monitoring Antimicrobial Resistance Trends (SMART). Antimicrobial Agents and Chemotherapy, 57(7), 2981-2988. doi: 10.1128/AAC.00971-12

15. Miller, B. M., \& Johnson, S. W. (2016). Demographic and infection characteristics of patients with carbapenem-resistant Enterobacteriaceae in a community hospital: Development of a bedside clinical score for risk assessment. American Journal of Infection Control, 44(2), 134-137. doi: 10.1016/j. ajic.2015.09.006

16. Thaden, J. T., Lewis, S. S., Hazen, K. C., Huslage, K., Fowler, Jr., V. G., Moehring, R. W., Chen, L. F., Jones, C. D., Moore, Z. S., Sexton, D. J., \& Anderson, D. J. (2014). Rising rates of carbapenem-resistant Enterobacteriaceae in community hospitals: A mixed-methods review of epidemiology and microbiology prac- tices in a network of community hospitals in the southeastern United States. Infection Control \& Hospital Epidemiology, 35(8), 978-983. doi: 10.1086/677157

17. lacovelli, V., Gaziev, G., Topazio, L., Bove, P., Vespasiani, G., \& Finazzi Agrò, E. (2014). Nosocomial urinary tract infections: A review. Urologia, 81(4), 222-227. doi: 10.5301/uro.5000092

18. Di Pasquale, M., Henchi, S., Vanoni, N., \& Blasi, F. (2017). Cardiovascular complications in patients with community-acquired pneumonia. Community Acquired Infection, 4(2), 23-31.

Retrieved from http://www.caijournal.com/article.asp?issn $=2225$ 6482 ; year $=2017$; volume $=4$; issue $=2 ;$ ppage $=23$; epage $=31$; aula $\mathrm{st}=\mathrm{Di}$

19. Salerno, F., Borzio, M., Pedicino, C., Simonetti, R., Rossini, A., Boccia, S., Cacciola, I., Burroughs, A. K., Manini, M. A., La Mura, V., Angeli, P., Bernardi, M., Dalla Gasperina, D., Dionigi, E., Dibenedetto, C., \& Arghittu, M. (2016). The impact of infection by multidrug-resistant agents in patients with cirrhosis. A multicenter prospective study. Liver International, 37(1). doi: 10.1111/ liv. 13195

20. Guh, A. Y., Bulens, S. N., Mu, Y., Jacob, J. T., Reno, J., Scott, J., Wilson, L. E., Vaeth, E., Lynfield, R., Shaw, K. M., Vagnone, P. M., Bamberg, W. M., Janelle, S. J., Dumyati, G., Concannon, C., Beldavs, Z., Cunningham, M., Cassidy, P. M., Phipps, E. C., Kenslow, N., Travis, T., Lonsway, D., Rasheed, J. K., Limbago, B. M., \& Kallen, A. J. (2015). Epidemiology of carbapenem-resistant Enterobacteriaceae in 7 US communities, 2012-2013. JAMA, 314(14), 1479-1487. doi: 10.1001/jama.2015.12480

21. Coccolini, F., Sartelli, M., Catena, F., Montori, G., Di Saverio, S., Sugrue, M., Ceresoli, M., Manfredi, R., \& Ansaloni, L. (2015). Antibiotic resistance pattern and clinical outcomes in acute cholecystitis: 567 consecutive worldwide patients in a prospective cohort study. International Journal of Surgery, 21, 32-37. doi: 10.1016/j.ijsu.2015.07.013

22. Garrido, A., Seral, C., Gude, M. J., Casado, C., González-Domínguez, M., Sáenz, Y., \& Castillo, F. J. (2014). Characterization of plasmid-mediated $\beta$-lactamases in fecal colonizing patients in the hospital and community setting in Spain. Microbial Drug Resistance, 20(4), 301-304. doi: 10.1089/mdr.2013.0109

23. Alexopoulou, A., Papadopoulos, N., Eliopoulos, D. G., Alexaki, A., Tsiriga, A., Toutouza, M., \& Pectasides, D. (2013). Increasing frequency of gram-positive cocci and gram-negative multidrugresistant bacteria in spontaneous bacterial peritonitis. Liver International, 33(7), 975-981. doi: 10.1111/liv.12152

24. Morsi, S. S. (2016). Comparative evaluation of phenotypic and genotypic methods for detection of carbapenemases in clinically significant Klebsiella pneumonia isolates. Egyptian Journal of Medical Microbiology, 25, 109-116.

25. Sekyere, J. O., Govinden, U., \& Essack, S. (2015). The molecular epidemiology and genetic environment of carbapenemases detected in Africa. Microbial Drug Resistance, 22(1), 59-68. doi: 10.1089/mdr.2015.0053

26. Memish, Z. A., Assiri, A., Almasri, M., Roshdy, H., Hathout, H., Kaase, M., Gatermann, S. G., \& Yezli, S. (2015). Molecular characterization of carbapenemase production among Gram-negative bacteria in Saudi Arabia. Microbial Drug Resistance, 21(3), 307314. doi: 10.1089/mdr.2014.0121 